\title{
Implantação e Ampliação da Cultura Cafeeira e a formação do Es- tado Nacional
}

\author{
Implementation and Extension of coffee culture construction of the National State
}

Magno Fonseca Borges', Thiago de Souza dos Reis².

\begin{abstract}
Resumo
Neste artigo buscamos compreender as mudanças econômicas e demográficas ocorridas no Médio Vale do Paraíba Fluminense, a partir de uma perspectiva que avalia as transformações sociais como vinculadas a construção do Estado Nacional Brasileiro.

Palavras-Chave: Vale do Paraíba. Cultura Cafeeira. Império do Brasil.
\end{abstract}

Como citar esse artigo. Borges MF, Reis TS. Implantação e Ampliação da Cultura Cafeeira e a formação do Estado Nacional. Revista Mosaico. 2014 Jan./Jun.; $05 \quad$ (1): 11-19.

\begin{abstract}
In this article we try to understand the economic and demographic changes in the Medium Vale do Paraíba Fluminense, from a perspective that evaluates the social transformations linked to the construction of the Brazilian National State. Keywords: Vale do Paraíba. Coffee culture. Empire of Brazil.
\end{abstract}

\section{Aspectos introdutórios}

O texto em tela não deve ser percebido como um trabalho terminado. Seus apontamentos refletem algumas das observações preliminares acerca dos projetos de pesquisa, ainda em fase exploratória de desenvolvimento. Como todo texto, este também não é frutos de inquietações exatamente originais, visto que a formulação de sua questão emergiu da análise de fração da produção historiográfica que se deteve sobre a região de Vassouras, e seu confronto com as fontes textuais de origens jurídica e eclesial, preservadas e acessíveis, atualmente, no escritório técnico do Instituto do Patrimônio Histórico e Artístico Nacional (IPHAN), localizado na cidade de Vassouras. ${ }^{1}$

O que aqui se propõe, passa por uma questão relativamente simples: É possível, compreender as mudanças econômicas e demográficas que tiveram ocorrência na Região, partindo de uma perspectiva que avalia as transformações sociais como vinculadas a construção do Estado Nacional Brasileiro? A resposta é positiva. Esta verificação se deu a luz da observância das grandes transformações sociais e econômicas que

1 As pesquisas foram realizadas entre os anos de 2005 e 2013. Aquele instante, a coleção de documentos que pesquisamos estava sob a guarda da Universidade Severino Sombra através de seu Centro de Documentação Histórica da USS (CDH) reconfiguraram o mundo moderno. Trata-se portanto, de reconfigurar o papel da implantação da cultura cafeeira, pautada na mão de obra escrava, em sua íntima conexão com o mercado mundial e a emergência da classe senhorial na conformação e consolidação do Império brasileiro. Para tanto, dialogaremos mais abertamente, e de modo continuado, com duas importantes referências: (1) E o Vale era o escravo - Vassouras, século XIX. Senhores e escravos no Coração do Brasil de Ricardo Salles, ${ }^{2}$ e (2) O Vale do Paraíba escravista e a formação do mercado mundial do café no século XIX de Rafael Marquese e Dale Tomich. ${ }^{3}$

\section{Configurações e Reconfigurações da Serra acima: café, mercado mundial e ocupação}

A ocupação econômica e demográfica do Vale do Paraíba Fluminense e os processos sociais que desencadearam alí uma das mais intrigantes epopéias da história brasileira, a rápida intensificação da cultura cafeeira, ainda encontra lugar para o desenvolvimento

2 SALLES, Ricardo. E o Vale era escravo. Vassouras, século XIX. Senhores e Escravos no coração do Império. Rio de Janeiro: Civilização Brasileira, 2008.

3 MARQUESE, Rafael; TOMICH, Dale. O Vale do Paraíba escravista e a formação do mercado mundial do café no século XIX", in Keila Grinberg e Ricardo Salles (org.) O Brasil Imperial. 1 ed. Rio de Janeiro: Civilização Brasileira, v. 2

1. Doutorando do Programa de Pós-Graduação em História da Universidade Federal do Estado do Rio de Janeiro (PPGH/UNIRIO). Professor nos cursos de Licenciatura em História e Pedagogia da Universidade Severino Sombra.

2. Doutorando do Programa de Pós-Graduação em História da Universidade Federal do Estado do Rio de Janeiro (PPGH/UNIRIO). Professor no curso de graduação em História da Universidade Estácio de Sá. Professor no curso de graduação em Direito da Universidade Veiga de Almeida. 
de pesquisas. A principal referência sobre o tema, a obra de Stanley Stein, trata este instante de forma bastante laminar, muito porque seu objeto de estudo tinha uma delimitação temporal bastante definida: Os anos de 1850 e $1900 .{ }^{4}$

Quando se trata o momento anterior, aquele da introdução da cultura cafeeira, de certo modo, forjouse a idéia de que esta cultura e a adesão massiva ao sistema escravista se deu como mero desdobramento da ocupação anterior e/ou simples perspectiva da ampliação das demandas por gêneros de alimentos após 1808. Fato que resultou da não observância do papel do desenvolvimento de um mercado mundial capitalista e da emergência dos Estados Nacionais - e neste quadro o papel da classe senhorial na conformação e consolidação do Império brasileiro. $\mathrm{O}$ instante compreendido entre a chegada da Corte Real Portuguesa e sua fixação na cidade do Rio de Janeiro e o fim do tráfico atlântico de pessoas em 1850, sempre foram apresentados de forma introdutória ou capitular, repisando informações construídas há muito pela historiografia. Esta longa trajetória abarca obras importantes e que se estendem desde os estudos memorialistas como Jorge Pinto ${ }^{5}$ e Ignácio Raposo, ${ }^{6}$ escritos à década de 1930 , passando pela clássica obra de Stanley Stein, ${ }^{7}$ e chegando a estudos mais recentes, como os de Rogério Ribas, ${ }^{8}$ Adelci Santos ${ }^{9}$ e Robert Slenes. ${ }^{10}$

As redefinições políticas que influíram na nova ordem de ocupação econômica e demográfica da região da Serra Acima, o Médio Vale do Paraíba Fluminense, não podem mais ser revisitadas apenas como um processo simplista de suas atividades anteriores, qual fossem (1) a de parte do cenário desenhado a partir da abertura do caminho novo (1705) que ligava as regiões mineiras ao porto do Rio de Janeiro, fazendo encurtar o caminho anteriormente transcorrido, nomeado por caminho velho, (2) ou ainda do momento imediato posterior, aquele da expansão da produção de alimentos para o abastecimento da Cidade do Rio de Janeiro, após a chegada da Família Real Portuguesa, em 1808, que promoveu grande impacto demográfico no lugar. É correto que, no tocante ao primeiro caso, a abertura do caminho novo propiciou as condições materiais para a fixação de pequenos posseiros e sitiantes além da formação de hospedarias para pouso de tropas, assim como seus derivados, as pequenas atividades de produção de alimentos e fixação de pessoas no território, o que justificou a criação das freguesias de Nossa Senhora da Conceição da Serra Acima da Roça do Alferes (1739)

4 STEIN, Stanley J. Vassouras Un Muicipio Brasileiro do Café: 1850-1900. RJ: Nova Fro 1990 [1957].

5 PINTO, Jorge. Fastos Vassourenses. Vassouras, Editora Fundação $1^{\circ}$ de Maio, 1935.

6 RAPOSO, Ignácio. História de Vassouras. $2^{\mathrm{a}}$ ed. Niterói, SEEC-RJ, 1978

7 STEIN, Stanley J. Op. Cit.

8 RIBAS, Rogério de Oliveira. Tropeirismo e escravidão: um estudo das tropas de café das lavouras de Vassouras, 1840-1888. Dissertação de Mestrado, Universidade Federal do Paraná, 1989.

9 SANTOS, Adelci Silva dos. À sombra da fazenda: a pequena propriedade agrícola na economia

de Vassouras oitocentista. Dissertação de Mestrado, Universidade Severino Sombra, 1999.

escrava (Brasil Sudeste, século XIX). Rio de Janeiro: Nova Fronteira, 1999. e de Nossa Senhora da Conceição de Sacra Família do Caminho Novo do Tinguá (1750). Certo ainda é que a chegada da Família Real, em 1808, promoveu afluxo por novas cotas de gêneros alimentícios para suprir à expansão da demanda, o que garantiu as condições materiais ao incremento de seu entorno no que toca a produção de porcos, galinhas, milho e outros gêneros. Também é certo que a existência de caminhos e uma certa ordem de povoamento na Serra Acima favoreceu a implantação da plantation cafeeira a partir da década de $1820 .^{11}$

A compreensão da aceleração da produção cafeeira, como produto voltado ao mercado externo alinha-se a uma série de fatores interdependentes. Todo o quadro traçado daqui a frente, tem como referência básica o trabalho de Rafael de Bivar Marquese e Dale Tomich. ${ }^{12} \mathrm{O}$ primeiro, é aquele que o transformou de um produto de luxo para o consumo de massa. $\mathrm{O}$ café foi, no século XVI, um dos mais valiosos gêneros da agricultura a compor o circuito mercantil. ${ }^{13}$ Até o século XVII os árabes monopolizaram sua produção e comércio, que visava atender os hábitos refinados de ingestão após as refeições. Aclimatado com sucesso para produção em larga escala, nas colônias do novo mundo - Suriname, Martinica e Guadalupe - por volta da década de 1720, o café foi introduzido no mercado metropolitano. O cultivo e exportação foram ampliados nas possessões coloniais francesas, e passaram a representar $70 \%$ do comércio mundial do gênero. Tal produção se dava principalmente em Sant Domingues. Lá, a mesma saltou de 3.100 t. em 1755 para 32.000 t. em 1790. Contudo, a revolução que lá teve ocorrência entre 1791 e 1804, desestruturou completamente as plantations escravistas da colônia francesa e fez proclamar o segundo Estado soberano do novo mundo, o Haiti. Os impactos deste evento revolucionário retiraram Sant Domingues do mercado internacional do produto, o que desencadeou impactos profundos sobre as demais regiões produtoras. ${ }^{14}$

De saída, as possessões britânicas expandiram suas lavouras. A Jamaica, em 1790 obteve a produção de 1.000 t. Em fins do século XVIII, a produção já havia saltado para 6.000 t e em 1808, alcançou a produção de 13.500 t. A partir deste momento a produção jamaicana do gênero declinou. Embora não ocupassem a mesma topografia que a produção do açúcar, condição que não fazia gerar competição territorial entre as culturas, o mesmo não se dava por conta da mão de obra. A produção agrícola pautada na mão de obra escrava encontrou em 1808 um entrave: o findar do tráfico atlântico de escravos para as colônias inglesas. A mesma medida que havia um vácuo no que tocava a produção cafeeira para o abastecimento do mercado internacional, por conta

11 BOGES, M. F. Protagonismo e sociabilidade escrava na implantação e ampliação da cultura cafeeira. Vassouras (1821-1850). Dissertação de Mestrado apresentada ao programa de Mestrado em

História da USS, 2005.

13 BOGES, M. F. Protagonismo e sociabilidade escrava... Op. Cit.

14 MARQUESE, Rafael; TOMICH, Dale. Op. Cit. 
da saída de Sant Domingues deste cenário, o mesmo se dava no campo da produção de açúcar, visto ter sido aquela colônia francesa a maior produtora mundial do gênero. Neste sentido a opção jamaicana foi atender ao mercado açucareiro. ${ }^{15}$

Neste cenário internacional, se deu a expansão da cultura do açúcar e do café em Cuba. O tráfico atlântico de escravos foi estimulado o que o tornou um dos principais motores da economia escravista cubana. Quando do advento da revolução em Sant Domingues, a ilha já contava com um importante sistema de tráfico, que envolveu traficantes hispano-cubanos e principalmente ingleses e norte americanos. A produção cubana em 1807 chegou a 1.000 t. Saltou para 4.600 t em 1810 e para 10.000 t em 1820. Mas Vale destacar: Até este momento, nenhuma outra região produtora chegou a atingir o pico de produção alcançado por Sant Domingues de $32.000 \mathrm{t}$ em $1790 .{ }^{16}$

Foi neste quadro, apresentado aqui de forma sintética, que o Brasil entrou no mercado internacional do gênero. $\mathrm{O}$ café foi introduzido no Estado do GrãoPará e Maranhão na década de 1720 (no mesmo movimento que promoveu sua introdução na Martinica e Suriname). Por volta da década de 1780 foi aclimatado também nas chácaras e quintais do Rio de Janeiro sem, contudo, de sua aclimatação e plantio, se verificar incremento econômico. ${ }^{17}$ Até o fim do século XVIII seu cultivo era meramente doméstico e ornamental, com pouca representatividade comercial. A média de produção anual no instante de 1797 e 1811 foi de 400 t. Mas a produção foi alargada com folego, a partir de então. Entre os instantes de 1812 e 1816 a média anual da produção brasileira saltou para $1.500 \mathrm{t}$ e para o instante posterior delimitado pelos anos de 1817 e 1821, esta média passou a 6.100 t. Com o iniciar da década de 1820 a produção cafeeira continuou a ser dilatada. Saltou para 13.500 t a média entre 1822 e 1823 e daí explodiu para $67.000 \mathrm{t}$ em 1833, atingindo sozinho o pico da produção de Sant Domingues observada em 1790. Deste momento em diante as cifras só fizeram

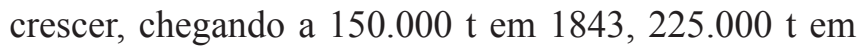
1860 e 350.000 t em 1870. O Brasil reinou soberano na produção e exportação do gênero ao longo de todo este instante, tendo por único competidor, mesmo assim com produção muito inferior, a colônia holandesa, não escravista, de Java, na Indonésia. ${ }^{18}$

A existência de tamanha produção somente foi possível por uma combinação de fatores, que ao mesmo tempo eram condicionadas e condicionantes das alterações sem precedentes, que forjaram o mundo moderno. Este conjunto complexo e interconectado de fenômenos, políticos, econômicos e sociais fizeram ruir os antigos monopólios, que foram substituídos

\section{Idem.}

15 Idem

16 Idem.

17 Cf. SALLES, Ricardo. E o
sociabilidade escrava... Op. Cit.

18 MARQUESE, Rafael; TOMICH, Dale. Op. Cit por tratados de livre comércio. Por esta vertente, ao mesmo tempo em que as antigas colônias atlânticas estavam abertas à receber produtos das mais diferentes vertentes industrias, por outro lado, abriu o mercado as commodities produzidas através do novo sistema. Dito de outra forma, a industrialização, urbanização e crescimento demográfico, ao mesmo tempo em que transformaram os países industrializados em exportadores de produtos industriais, também os tornaram dependentes de fornecedores externos de artigos para a indústria. ${ }^{19}$ Neste processo, por exemplo, a Inglaterra num intervalo de 70 anos (1780 e 1850) quadruplicou seu volume de importações. Ainda, para além dos produtos utilizados de forma direta na produção industrial, como foi o caso do algodão norteamericano, o mercado internacional foi configurado e configurou novos padrões de consumo de commodities pelas classes médias e operárias, como foi o caso do açúcar cubano e do café brasileiro. ${ }^{20}$

Foi no bojo deste mercado mundial que o Brasil, em via de mão dupla, se configurou e foi configurado como Estado Nacional. Neste sentido, reconfigurou e foi reconfigurado pela a região do médio Vale do Paraíba. ${ }^{21}$ Como dito acima, é certo que a trajetória de ocupação anterior, favoreceu este novo momento. Os principais fatores indicados pelos autores que historiaram a região à apontar para a naturalidade do processo faziam remessa a existência de disponibilidade de grandes áreas em terras virgens e um importante e complexo sistema de transporte, que incluía os caminhos que cruzavam a região e, ainda, o pleno domínio do transporte de cargas, por meio das tropas de muares. Para além destes dados, a historiografia aponta também à existência do vigoroso tráfico atlântico de escravos, controlado por negociantes do Rio de Janeiro. 22

Mas como bem observou Marquese e Tomich ${ }^{23}$ esta infra-estrutura, já existente quando dos eventos revolucionários de Sant Domingues, não foi mobilizada para a cafeicultura. Contrário a isso, a região continuou a ser parcamente ocupada. ${ }^{24}$ Entre 1790 e 1800 a resposta dos senhores escravistas aos impactos gerados pela saída de Sant Domingues do mercado mundial, se deu pelo incremento à cultura do açúcar. As principais regiões brasileiras produtoras do gênero foram Campos

19 Cf. SALLES, R.; BORGES, Magno Fonseca. (2009) Vassouras - 1830-1850: poder local e rebeldia escrava. In: Carvalho, José Murilo; Neves, Lúcia Maria Bastos Pereira das. (Org.) Repensando o Brasil do Oitocentos. Cidadania, Política e Liberdade. $1^{\circ}$ ed. Rio de Janeiro: Civilização Brasileira, 2009, v. 1, p. 437-460. Cf. TOMICH, Dale (2011). Pelo prisma da escravidão. Trabalho, Capital e Economia Mundial. São Paulo, Editora da Universidade de São Paulo. 20 Cf BORGES, Magno Fonseca; GRINBERG, Keila; SALLES, R (2009). Rebeliñ escras 20 Cf. BORGES, Magno Fonseca; GRINBERG, Keila; SALLES, R (2009). Rebeliōes escravas antes da exhḩ̧ão do tráfico. In: Grinberg, Keila; Salles, Ricardo. (Org.). O Brasil Imperial. 1ed.

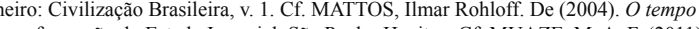
saquarema: a formação do Estado Imperial. São Paulo: Hucitec. Cf. MUAZE, M. A. F. (2011). O Vale do Paraiba e a dinâmica Imperial. In: LERNER, Dina; MISZPUTEN, Francis (Orgs). Inventário das Fazendas do Vale do Paraiba Fluminense - fase III. 1ed. Rio de Janeiro: INEPAC/ ICCV. Disponível em: http://www.institutocidadeviva.org.br/inventarios/sistema/wp-content/ uploads/2010/12/15 mariana muaze.pdf. Cf. SALLES, R.; BORGES, Magno Fonseca. A morte do barão de Guaribu. Ou o fio da meada. Heera (UFJF. Online), v. 7. 2012. Disponível em: http://www. uff.br/heera/files/2009/11/A-morte-do-bar\%C3\%A3o-de-Guaribu.Hera .pdf.

21 SALLES, R.; BORGES, Magno Fonseca. A morte do barão de Guaribu... Op. Cit.

22 Cf. FRAGOSO, João; FLORENTINO, Manolo. O arcaísmo como projeto. Rio de Janeiro: Diadorim, 1993.

Diadorim, 1993.

24 SALLES, R.; BORGES, Magno Fonseca. A morte do barão de Guaribu... Op. Cit. 
dos Goitacás e Baixada Fluminense, na Província do Rio de Janeiro, e Campinas na Província Paulista. Mas no que toca ao médio Vale do Paraíba fluminense, a região permanecia parcamente ocupada. Como exceção, apenas algumas unidades voltadas a produção de açúcar, como a fazenda do Pau Grande. ${ }^{25}$

Para Marquese e Tomich, ${ }^{26}$ a virada deste quadro se deu com a fuga da Família Real Portuguesa para o Rio de Janeiro. Concordamos em definitivo com o marco. Para delimitá-lo, os autores apresentam dois fatores, quais sejam (1) as estratégias adotadas pelo governo joanino para estimular a produção e comércio de gêneros de primeira necessidade a suprir os impactos provocados pelo rápido adensamento demográfico com a instalação da Corte (2) e a aberturados portos.

Nossa concordância com os dois fatores se faz na medida em que os mesmos não podem ser verificados de forma dissociada. $\mathrm{O}$ forte estímulo a produção de alimentos para o abastecimento da Corte, envolvia não apenas a urgência à produção de milho, farinha, galinhas e porcos - entre outros gêneros à suprir um novo mercado. ${ }^{27}$ Tocava também a investimento de infra-estrutura, como de fato ocorreram com a abertura de duas importantes variantes do Caminho Novo, quais fossem: as estradas do Comércio e da Polícia. ${ }^{28}$ Mas, para além do fato da demanda por gêneros de alimento estava a nova condição da cidade do Rio de Janeiro: Corte do maior reino atlântico do mundo de então.

Por um lado, ao suprir com alimentos a Corte, fazia-se também afluir capitais para investimento e reinvestimento, tanto na continuidade de produção, mesmo que apenas por mais algum tempo, como também ao incremento da plantation. Muito embora tais recursos fossem relativamente parcos, frente às demandas de implantação de grandes unidades cafeeiras, é certo que deste capital emergiu uma série de micros, pequenos e talvez até médios senhores rurais do lugar. ${ }^{29}$ Por outro lado, a abertura de novos caminhos e o papel estratégico de celeiro da Corte dava a ocupação da região um papel relevante, levando-a da periferia ao centro dos interesses do Estado. Os habitantes da região passaram a freqüentar e serem freqüentados, a incorporar e a serem incorporados pela Corte em sua estrutura militar e burocrática. ${ }^{30}$

Já a abertura dos portos após 1808 , teve como significação a queda do antigo regime, onde as atividades econômicas se davam a guisa das práticas mercantilistas de reserva de mercado para o escoamento de produtos coloniais e a interferência política sob a forma de monopólios. A abertura dos portos invertia esta ordem, fazendo colocar os senhores escravistas em conexão direta ao mercado mundial.
A política joanina direcionada a antiga zona proibida, ou seja, o médio Vale do Paraíba, além de promover a abertura das estradas da Polícia e Comércio, as margens das quais emergiram dois dos maiores municípios cafeicultores mundiais do século XIX, Vassouras e Valença, dinamizou a doação de sesmarias, com o claro indicativo de inverter a ordem anterior estabelecida. A doação de sesmaria se constituiu como um dos principais instrumentos do Estado Português para normatizar a distribuição das terras destinadas à produção. O seu uso efetivo se converteu em poderosa política de povoamento. Como seu principal caráter era o estímulo à produção, sua doação envolvia a necessidade de o recebedor comprovar ter meios de transformar terras incultas em cultas. Dito de outro modo, os sesmeiros deveriam ter capital para investimento, e neste caso, incluiam-se escravos. Para a obtenção de sesmarias, era necessário configurar a possibilidade de transformá-la, em curto espaço de tempo, em terras produtivas.

Esta política de doação de sesmaria, além do estímulo a produção - visto suas regras que incluía a possibilidade de reversão da doação, em caso de o sesmeiro não atender as perspectivas de produção - se configurou em poderosa ferramenta de ocupação social e econômica. Como exemplo, a origem da Vila de Vassouras está intimamente ligada a antiga Sesmaria de Vassouras e Rio Bonito, cujos sesmeiros foram Francisco Rodrigues Alves e Luiz Homem de Azevedo. ${ }^{31}$ Se por um lado, as questões da normatização e distribuição das terras passaram a estratégico dentro do quadro de ocupação da Serra Acima, é certo que também gerou tensões, e fez produzir um aparato burocrático a suas resoluções. Não se pretende aqui, tratar o fato de forma pormenorizada. Apresenta-se, contudo, que o processo desencadeado pelo Estado - de ocupação da região - não ficou isento de tensões, que se davam entre posseiros, destes com sesmeiros, entre sesmeiros e por vezes até entre os sesmeiros e o Estado. ${ }^{32}$ Tais contendas promoveram os mais diferentes conflitos, expressos em diversificadas tipologias documentais de caráter jurídico, como os de adjudicação de árvores e benfeitorias, processos criminais e os de medição e demarcação.

Em 1818, os herdeiros da sesmaria de Vassouras 
e Rio Bonito, solicitaram ao Dr. Manoel Rodrigues Pacheco e Moraes a abertura de uma ação judicial de medição, demarcação e aviventação dos rumos daquela sesmaria. Tal solicitação revela parte da política de Estado, visto ser aquele Dr. Manoel, o Juiz das sesmarias da Corte e Cidade de São Sebastião do Rio de Janeiro. ${ }^{33}$ Ora, dois aspectos aqui são relevantes (1) o da existência de um juizado, com todos os seus aparatos, quais fossem, Escrivão, Oficiais de Justiça e Piloto, para tratarem das questões de Sesmarias, portanto, questões de terra e (2) a nomeação daquele juízo como das sesmarias da Corte e da Cidade do Rio de Janeiro, que reforça o acima disposto sobre a Serra Acima incorporar e ser incorporada a Corte, por meio de situações das mais diversificadas, como o fato de um dos herdeiros que se remeteu a solicitação de abertura processual ao Dr. Manoel Rodrigues - que além de Juiz de Sesmarias era também Cavaleiro da Ordem de Cristo - ser um Guarda-Mór João Teixeira Gomes, que por sua patente incorporou e foi incorporado ao aparelho militar da Corte. ${ }^{34}$

Como se percebe, a trajetória do médio Vale do Paraíba fluminense de zona proibida a maior produtora mundial de café, marcou e foi marcada por um intenso processo de reocupação econômica, demográfica e social. O Gráfico 1 apresenta a evolução da distribuição de sesmarias em Valença entre 1797 e 1835.

Apenas uma em 1797 e duas entre 1801 e 1805, as concessões saltaram para 23 nos cinco anos posteriores. Entre 1811 e 1815, elas atingiram seu pico com 112 novas concessões e, em seguida, começaram a baixar. Em Vassouras, para onde não se dispõe dos mesmos tipos de dados de forma sistematizada, as fontes que historiam a ocupação da região confirmam que a mesma dinâmica pode ter se repetido.
As políticas do governo joanino de incremento a ocupação econômica, demográfica e social do médio Vale do Paraíba, fizeram derrocar a idéia de zona proibida. Suas relações íntimas com a abertura dos portos a partir de 1808 estavam imersas em um mesmo quadro internacional. Como resultado prático, em aspectos gerais, este momento incidiu sobre (1) a alta especialização das regiões produtoras de commodities para o abastecimento das regiões industrializadas e (2) o avanço da escravidão, numa conjuntura internacional antiescravista. ${ }^{35}$

Neste instante tenso, no tocante a mão de obra escrava, verifica-se o restringir dos pontos de absorção de escravos pelo mercado transatlântico. Contudo, como nunca antes na história da humanidade, se viu elevar com tanto fôlego os volumes de gentes escravizadas. Por volta de 1770 existia quase 2,5 milhões de escravos africanos e afro-descendentes espalhados por todo o novo mundo. No curso de oitenta anos, o sistema escravista foi desarraigado em antigas áreas de produção, como as fazendas de açúcar e café de Sant Domingues, Martinica, Jamaica, Barbados, Essequibo e Demerara, das fazendas de cacau da Venezuela, das minas do México e do Peru. Mas o mesmo não ocorreu com o Sul dos Estados Unidos, a ilha de Cuba e o Império do

Brasil. Em 1850, estas três regiões escravistas, sozinhas, detinham 5,7 milhões de escravizados. Esta intensa elevação de aproximados $130 \%$, se comparado com 1770, foi acompanhada da elevação de produção do commodities. ${ }^{36}$

Especialistas por seu turno, Estados Unidos (algodão) Cuba (açúcar) e Brasil (Café) fizeram ampliar, suas exportações. No mesmo compasso, estas três regiões alargaram as fronteiras de suas áreas produtivas,

Gráfico 1. Valença - distribuição de sesmarias por períodos - 1797-1835

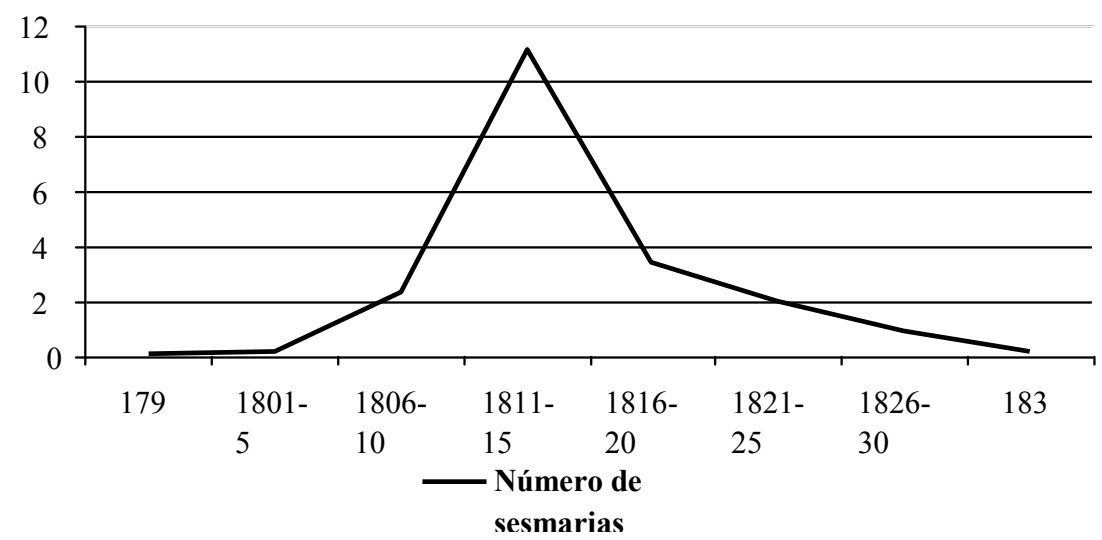

Fonte. Leoni Iório, Valença de ontem e de hoje. (Subsidios para a história do município de Marquês de Valença - 1789-1952), Valença-RJ, 1953.

33 CDH-USS: 101663451016. Medição e Demarcação (1818). autores: José Teixeira Gomes e Antonio Alves de Lacerda; falecidos: Luiz Homem de Azevedo e Fellis Rodrigues Alves. 34 Idem, 35-39.
35 Cf. SALLES, R.; BORGES, Magno Fonseca. (2009) Vassouras - 1830-1850 36 Cf. SALLES, Ricardo. E o Vale era escravo. Op. Cit. Cf. BOGES, M. F. Protagonismo e sociabilidade escrava... Op. Cit. 
e passaram a operar na tênue fronteira que delimitava o avanço do escravismo em seu embate com o avanço dos movimentos antiescravistas. Assim a modernidade configurava e era configurada por este embate. Estas três fronteiras de produção de commodities ao mercado mundial, se fizeram encher de cativos de origem africana na lavoura de gêneros de exportação. Os Estados Unidos principalmente por meio da reprodução vegetativa e Brasil e Cuba por meio do tráfico atlântico. ${ }^{37}$

Foi neste quadro, que o Brasil impactou e foi impactado pelas novas configurações do mundo moderno e marcou e foi marcado pela derrocada do escravismo colonial e ascensão do escravismo nacional. Passou a configurar e se reconfigurar em novos padrões de consumo participando ativamente de dois eixos comerciais, aquele que o tornou maior exportador de café e importador de escravos. Emergiu enquanto Estado Nacional operando num novo cenário, marcado por profundas tensões antiescravistas. ${ }^{38}$ Como resposta, emergiu e se consolidou a partir do tráfico atlântico e foi o último país do mundo a promover a abolição deste sistema. Stein elaborou um quadro demonstrando a evolução da população escrava no Brasil, com o aumento na casa de $40 \%$ entre os anos de 1798 e 1850 . Para o primeiro ano ele encontrou um total de 1.500 .000 escravos, para o seguinte 2.500 .000 , o que resulta uma variação média anual de $0,77 \% .{ }^{39}$ Tal evolução se deu por meio do transporte e aquisição massiva de africanos por meio de tráfico legal e também ilegal. $\mathrm{O}$ ar de mudanças que se respirava durante a consolidação do Brasil como Estado Nacional, voltado ao mercado internacional de commodities, se tornou um vendaval que varreu a região da Serra Acima. Sua ocupação econômica foi acelerada, fazendo alargar o volume de pés de café plantados. Neste compasso se deu a ocupação demográfica.
Para a região, um enorme afluxo de pessoas das mais diversas procedências a atuarem numa arena marcada pela tensa relação entre senhores e escravos. ${ }^{40}$

Para apoiar a compreensão desde movimento em Vassouras, optou-se por realizar investigação em inventários pos morte. Identificou-se 223 inventários abertos até o anos de 1850. Destes apenas 1 faz remessa ao instante anterior a 1821. Para esta análise, se examinou os dados de avaliação de cativos contidos nos 222 inventários que tiveram por abertura os anos compreendidos entre 1821 e 1850 . Partindo do patamar de 479 escravos arrolados nos inventários, competentes ao intervalo 1821-1825, se chegam ao momento de 18461850 com um total de 2.629 cativos, o que representa elevação de $81,78 \%$.

A tabela I apresenta o número de pés de café e de escravos encontrados em inventários entre os anos de 1821 e 1850, para Vassouras. Mostram que a ampliação da área plantada se fez presente de forma acelerada ao longo de praticamente todo o intervalo. Partindo do patamar de 149.996 pés de café, contabilizados para o período de 1821-1825, para os 5 anos posteriores, se observa a elevação na casa de $34 \%$ no número de cafeeiro e, em paralelo, uma retração de $11,27 \%$ do número de escravos. Observando os movimentos numéricos proporcionais de 1831-1835, no confronto com o intervalo anterior, o número de cafeeiros cresceu mais $66,78 \%$ e o de cativos $35,29 \%$. O intervalo 1836 1840 é o que marca a mais impressionante elevação percentual, tanto do número de pés de café, quanto de cativos. Para o primeiro, a elevação é de $221,67 \%$, enquanto o segundo é de $135,39 \%$, sendo este instante o pico de aceleração. Para os momentos em posterior, continua-se a aceleração, porém em cadência pouco menor. O intervalo 1841-1845 contou com a elevação

Tabela I: pés de café e escravos entre 1821 e 1850

\begin{tabular}{|c|c|c|c|c|c|c|}
\hline Período & $\begin{array}{l}\mathrm{N}^{0} \text {. Pés de } \\
\text { café }\end{array}$ & $\%$ & $\begin{array}{c}\text { \% em relação ao } \\
\text { período imediato } \\
\text { anterior }\end{array}$ & $N^{0}$. de escravos & $\%$ & $\begin{array}{c}\text { \% em relação ao } \\
\text { período imediato } \\
\text { anterior }\end{array}$ \\
\hline $1821-1825$ & 149.996 & 2,45 & - & 479 & 5,94 & - \\
\hline $1826-1830$ & 201.160 & 3,3 & 34,11 & 425 & 5,27 & $-11,27$ \\
\hline $1831-1835$ & 335.504 & 5,5 & 66,78 & 575 & 7,14 & 35,29 \\
\hline $1836-1840$ & 1.079 .232 & 17,67 & 221,67 & 1457 & 18,1 & 153,39 \\
\hline $1841-1845$ & 2.168 .551 & 35,52 & 100,93 & 2490 & 30,912 & 70,89 \\
\hline $1846-1850$ & 2.171 .241 & 35,56 & 0,12 & 2629 & 32,638 & 5,58 \\
\hline total & 6.105 .684 & 100 & & 8.055 & 100 & \\
\hline
\end{tabular}

Fonte. Compilação dos dados apresentados por SANTOS. Adelci Silva dos. À Sombra da Fazenda: A Pequena Propriedade Agrícola na Economia de Vassouras Oitocentista. Vassouras: Dissertação de Mestrado. 1999. Capítulo 2. e BORGES, M. F. Protagonismo e sociabilidade escrava na implantação e ampliação da cultura cafeeira em Vassouras (1821-1850). Dissertação de apresentada ao Programa de Mestrado em História da Universidade Severino Sombra, 2005. Capítulo 1. 
de 100,93\% no número de pés de café, enquanto o percentual de escravos foi ampliado em 70,89\%. Para o último instante do período que compõe esta proposta de estudo, ocorre inversão na lógica de ampliação dos índices percentuais de pés de café e de escravos. Embora as elevações percentuais sejam muito modestas, frente aos indicadores acima apresentados, é a única vez que se percebe a aceleração percentual do número de pés de café inferior ao de escravos. O crescimento percentual de pés de café é de $0,12 \%$, e o de escravos de 5,58\%.

$\mathrm{O}$ quadro acima foi importante à avaliação dos instantes que delimitam a introdução (1821-1835) e a ampliação (1836-1850) da cultura cafeeira. Contudo, estas fases não devem ser aqui compreendidas dentro de uma pespectiva capsular. É certo que os períodos se sobrepõem uns aos outros, principalmente nos momentos que se limitam. Ao propor tal delimitação, por um lado, como parece óbivio, pesou o fator matemático que permitiu categorizar 2 intervalos de 15 anos. Mas por outro lado, o que realmente permitiu a construção destas duas fases da cafeeicultura na região, enquanto categorias de análise histórica, são as conexões estabelecidas entre as variações núméricas e os movimentos econômicos e demográficos. Os dados demonstram que, $10 \%$ dos pés de café e $18 \%$ do total de escravos, arrolados nos inventários, se encontravam entre os anos de 1821 e 1835. Já os outros $90 \%$ dos cafezais e $82 \%$ dos cativos, entre os anos de 1836 e 1850 . Os primeiros quinze anos apontam para uma menor pressão demográfica, e mesmo da área plantada. Neste instante, em grande maioria dos inventários é recorrente a indicação, pés de café novos. Embora estas informações continuem a aparecer para o momento posterior, ao término da década de 1840 já se começam a encontrar algumas parcas referências a pés de café velho.
Para além do número de cafeeiros, observase também movimentos distintos no que toca o recrusdecimento do escravismo e a ampliação da exploração da mão de obra. O gráfico 2 , colado abaixo, indica uma queda permanente na razão de escravos por mil pés de café.

A linha de tendência polinomial indica uma acentuada queda na proporção de escravos para o trato dos cafezais, ao longo de toda a fase da implantação. No ano de 1835 esta linha está a risca, sob o número de 2 escravos para cada mil pés de café. A partir deste instante, se diminui a incidência da queda. A linha permanece até 1850, abaixo do patamar de 1835. Embora tenha sido um instante de recrusdecimento do tráfico atlântico quando o se deu o pico da aceleração número de cativos em mais de $150 \%$ no comparativo com o volume anterior - foi também o momento em que se parece ter encontrado uma média do percentual de cativos a atuar nos cafezais. Em comparação com o momento anterior - de forte aceleração na retração de número de escravos por mil pés de café - este instante foi marcado por uma variação pequena destes indicadores. A implantação e ampliação da cafeicultura em Vassouras deitam raízes sobre a própria formação do Estado Imperial.

\section{Conclusões preliminares}

A crescente do número de plantas de café na Serra Acima, está ligado aos movimentos que se configuraram e foram reconfigurados na emergência do mercado mundial de commodities do mundo moderno. Regiões produtoras como Cuba, Brasil e o sul dos Estados Unidos forjaram uma nova escravidão com intima

Gráfico 2: pés de café e escravos entre 1821 e 1850

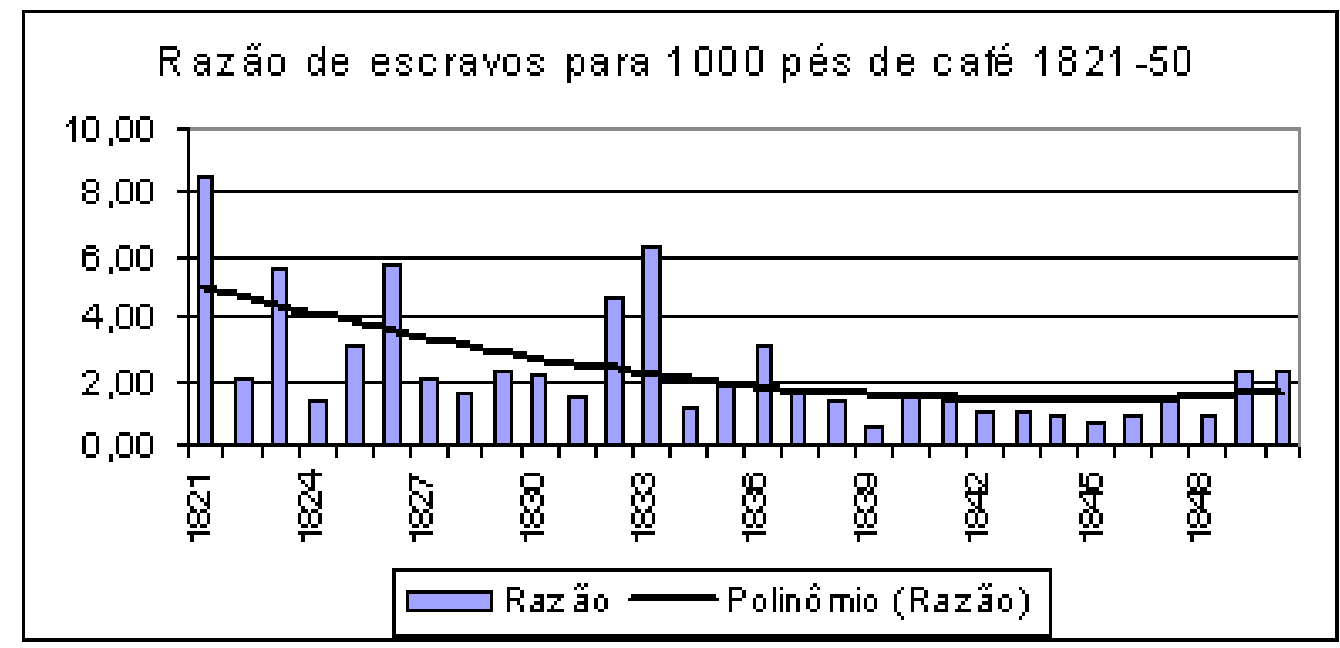

Fonte. Compilação dos dados apresentados por SANTOS. Adelci Silva dos. À Sombra da Fazenda: A Pequena Propriedade Agrícola na Economia de Vassouras Oitocentista. Vassouras: Dissertação de Mestrado. 1999. Capítulo 2. e BORGES, M. F. Protagonismo e sociabilidade escrava na implantação e ampliação da cultura cafeeira em Vassouras (1821-1850). Dissertação de apresentada ao Programa de Mestrado em História da Universidade Severino Sombra, 2005. Capítulo 1. 
interação com a construção dos Estados nacionais. A partir da década de 1820 , o Brasil tornou-se especialista na produção em larga escala de café, ao abastecimento da expansão internacional do mercado capitalista. No Brasil, este momento foi o mesmo da formação da classe senhorial enquanto processo simultâneo de formação do Estado imperial. A região fluminense, além de sua preeminência, foi à base social deste processo. Neste contexto, o regime escravista ultrapassou os limites da mera força de trabalho a garantia da produção e se configurou mesmo como instrumento de soldagem da classe. $\mathrm{O}$ antiescravismo se tornou uma das pautas da agenda política do século XIX. A contrariedade entre os movimentos que o desarraigaram de antigas zonas produtivas e por outro lado promoveram o inédito incremento do tráfico, principalmente para o Brasil, levou o sistema a compor o centro dos debates do Estado Brasileiro.

Estas tensões passaram pelo interior do próprio Império, por meio de suas instituições e agentes, entre os quais estavam os próprios senhores escravistas. Estes faziam parte do aparelho militar, ocupando cargos de Guardas-Mór, Capitães, Capitães-Mor. Faziam parte do aparato jurídico, tanto como juizes e como jurados. Faziam parte das Câmaras e se faziam representar no Legislativo da Província. Mas, para além de suas participações nos órgãos oficiais, constituíram organizações civis. Como exemplo, a Sociedade Promotora da Civilização, em 1832 (que, através de sua rede de relações com o legislativo da Província, promoveu a transferência da sede da Vila de Pati do Alferes para Vassouras) e a construção da Comissão Permanente para Conter Insurreições de Escravos (que criou cartilha sobre o modelo adequado para a administração da escravaria). Como resultado, este grau de homogeneidade, de autoconsciência e organização, foi o momento de construção do Império Brasileiro, onde a classe senhorial influiu na direção moral do Estado. ${ }^{41}$ Enquanto Estado nacional, a opção brasileira foi por se constituir como Estado Imperial com base na monocultura latifundiária, cuja classe dominante foi à classe senhorial.

\section{Referências}

\section{A) Fontes}

CDH-USS: 101663451016. Medição e Demarcação (1818). autores: José Teixeira Gomes e Antonio Alves de Lacerda; falecidos: Luiz Homem de Azevedo e Fellis Rodrigues Alves.

B) Bibliografia:

BRAGA, Greenhalgh H. F. Vassouras de ontem. Rio de Janeiro, Cia. Brasileira de Artes Gráficas, 1975.

BITTENCOURT, Fernando M. Vassouras, um pouco de sua história. Vassouras, Gráfica Palmeiras, 2001.

41 Cf. SALLES, Ricardo. E o Vale era escravo. Op. Cit. Cf. BOGES, M. F. Protagonismo sociabilidade escrava... Op. Cit.
BOGES, M. F. Protagonismo e sociabilidade escrava na implantação e ampliação da cultura cafeeira. Vassouras (1821-1850). Dissertação de Mestrado apresentada ao programa de Mestrado em História da USS, 2005.

BORGES, Magno Fonseca; GRINBERG, Keila; SALLES, R. Rebeliões escravas antes da extinção do tráfico. In: Grinberg, Keila; Salles, Ricardo. (Org.). O Brasil Imperial. 1ed. Rio de Janeiro: Civilização Brasileira, v. 1.

FRAGOSO, João; FLORENTINO, Manolo. O arcaísmo como projeto. Rio de Janeiro: Diadorim, 1993.

MARQUESE, Rafael; TOMICH, Dale. O Vale do Paraíba escravista e a formação do mercado mundial do café no século XIX", in Keila Grinberg e Ricardo Salles (org.) O Brasil Imperial. 1ed. Rio de Janeiro: Civilização Brasileira, v. 2. 2009

MACHADO, Lielza L. Vassouras - Recanto Histórico do Brasil. $3^{\mathrm{a}}$ ed. Vassouras, Gráfica Palmeiras, 2006.

MAPURUNGA, Marta Cursino. Pati do Alferes, Progresso e estagnação: uma história de alijamento político-econômico. Dissertação apresentada ao Programa de Mestrado em História da Universidade Severino Sombra em 2002.

MATTOS, Ilmar Rohloff. O tempo saquarema: a formação do Estado Imperial. São Paulo: Hucitec. 2004

MONTEIRO, Angelo F. Redes de Sociabilidade em Vassouras no século XIX - O Caso Benatar. Vassouras, Editor Autor, 2007.

MUAZE, M. A. F. (2011). O Vale do Paraíba e a dinâmica Imperial. In: LERNER, Dina; MISZPUTEN, Francis (Orgs). Inventário das Fazendas do Vale do Paraíba Fluminense - fase III. 1ed. Rio de Janeiro: INEPAC/ ICCV. Disponível em: http://www.institutocidadeviva.org.br/inventarios/sistema/ wp-content/uploads/2010/12/15_mariana_muaze.pdf

PINTO, Jorge. Fastos Vassourenses. Vassouras, Editora Fundação $1^{\circ}$ de Maio, 1935.

RAPOSO, Ignácio. História de Vassouras. 2ª ed. Niterói, SEEC-RJ, 1978. RIBAS, Rogério de Oliveira. Tropeirismo e escravidão: um estudo das tropas de café das lavouras de Vassouras, 1840-1888. Dissertação de Mestrado, Universidade Federal do Paraná, 1989.

SALLES, Ricardo. E o Vale era escravo. Vassouras, século XIX. Senhores e Escravos no coração do Império. Rio de Janeiro: Civilização Brasileira, 2008.

SALLES, R.; BORGES, Magno Fonseca. Vassouras - 1830-1850: poder local e rebeldia escrava. In: Carvalho, José Murilo; Neves, Lúcia Maria Bastos Pereira das. (Org.). Repensando o Brasil do Oitocentos. Cidadania, Política e Liberdade. $1^{\circ}$ ed. Rio de Janeiro: Civilização Brasileira, 2009, v. 1, p. 437-460.

SALLES, R.; BORGES, Magno Fonseca . A morte do barão de Guaribu. Ou o fio da meada. Heera (UFJF. Online), 2012. v. 7. Disponível em: http:// www.ufjf.br/heera/files/2009/11/A-morte-do-bar\%C3\%A3o-de-Guaribu. Hera_pdf.

SANTOS, Adelci Silva dos. À sombra da fazenda: a pequena propriedade agrícola na economia de Vassouras oitocentista. Dissertação de Mestrado, Universidade Severino Sombra, 1999.

SLENES, Robert W. Na senzala, uma flor. Esperanças e recordações na formação da família escrava (Brasil Sudeste, século XIX). Rio de Janeiro: Nova Fronteira, 1999.

STEIN, Stanley J. Vassouras Um Municipio Brasileiro do Café: 1850 - 1900. RJ: Nova Fronteira. 1990 [1957]

SOUZA, Alan de C. Querelas Políticas: Outra História no Caso Manoel Congo. Monografia de Conclusão do Curso em História. Universidade Severino Sombra. Vassouras, 2008

TAMBASCO, José Carlos V. A Vila de Vassouras e as Freguesias do Tinguá - Um Abordagem social e econômica dos tempos da colonização. Vassouras, Editor Autor, 2004

TELLES, Augusto Carlos da S. Vassouras, Estudo da Construção Residencial Urbana. Separata da Revista do Patrimônio Histórico e Artístico Nacional. Vol. 16. Rio de Janeiro, 1968. 
TOMICH, Dale. Pelo prisma da escravidão. Trabalho, Capital e Economia

Mundial. São Paulo, Editora da Universidade de São Paulo. 2011. 